\title{
Enhancing Hispanic Minority Undergraduates' Botany Laboratory Experiences: Implementation of an Inquiry-based Plant Tissue Culture Module Exercise
}

\author{
Dimuth Siritunga $^{1}$, Vivian Navas ${ }^{1} \&$ Nanette Diffoot $^{1}$ \\ ${ }^{1}$ Department of Biology, University of Puerto Rico Mayagüez, Mayagüez PR 00680, USA \\ Correspondence: Dimuth Siritunga, Department of Biology, University of Puerto Rico Mayagüez, Mayagüez PR \\ 00680, USA. Tel: 1-787-832-4040 x3113. E-mail: Dimuth.siritunga@upr.edu
}

Received: May 14, 2012 Accepted: June 1, 2012 Online Published: July 31, 2012

doi:10.5539/ies.v5n5p14 URL: http://dx.doi.org/10.5539/ies.v5n5p14

\begin{abstract}
Early involvement of students in hands-on research experiences are known to demystify research and promote the pursuit of careers in science. But in large enrolment departments such opportunities for undergraduates to participate in research are rare. To counteract such lack of opportunities, inquiry-based laboratory module in plant tissue culture was implemented in an undergraduate botany course impacting approximately 140 Hispanic minority students per year. In this module, spread throughout the semester, the students used African violet to gain experience in plant tissue culture techniques. The objective was for the students to learn how to take part of the plant from in vivo to in vitro culture. This required the establishment of aseptic techniques and the use of different media components to multiply plants under in vitro conditions. In depth assessment of gain-of content knowledge and gain-of confidence revealed that our inquiry-based approach allowed the students to learn while increasing their self-perception of scientific methodology. In three semesters, the students reported a 2.5 -fold overall increase in the post-module assessment for content knowledge compared to pre-module assessment. Similarly, approximately $85 \%$ of the students reported that they gained self-confidence in many aspects pertaining to conducting future research such as the use of primary literature, the design and performance of novel scientific experiments, and the formulation of a testable hypothesis. Though this lab module was solely in plant tissue culture, the inquiry-based nature of the exercise developed students' research skills and built confidence which is important in increasing retention of students in sciences.
\end{abstract}

Keywords: undergraduate, tissue culture, education assessment, African violet, inquiry-based, lab module

\section{Introduction}

Being involved in hands-on independent research as an undergraduate student has been positively correlated to the pursuit of careers in science (National Research Council, 2003; Russell et al., 2007; Lopatto, 2010). A well-established method of students gaining such experiences has been by conducting independent project in a research laboratory of a faculty member in their home institution. Similarly, more and more students, especially minorities, are finding higher number of opportunities to conduct independent research during the summer months away from their home institutions. Although such experiences lead to the "demystification of research", only a fraction of the student population is able to participate due to various reasons ranging from lack of knowledge of opportunities, limited faculty and/or institutional resources, limited space in research labs, family commitments etc. Due to these reasons, at the Department of Biology of the University of Puerto Rico Mayagüez (UPRM), of the approximately 1500 undergraduate majors only an estimated $8 \%$ of the students are able to conduct independent research during the academic year. Recognizing these limitations and the benefits of engaging students in the scholarship of science as early as possible, faculty and departments have begun to successfully implement research- or inquiry-based laboratory exercises in small-, medium- or large-enrollment courses throughout different curricula (Shaffer et al., 2010; Siritunga, Montero-Rojas, Carrero, Toro, Vélez, \& Carrero-Martínez, 2011; Wei \& Woodin, 2011).

Since the 1960s there has been a dramatic increase in the application of in vitro tissue culture techniques to various problems in basic plant biology, agricultural and horticultural crops as well as forestry. These applications can be broadly categorized into the following areas: cell behavior (studies focused on development, 
nutrition, primary and secondary metabolism, and pathology); plant modification and improvement (studies in the production of interspecific and intergeneric hybrids through embryo rescues, isolation of genetic variants, and the production of genetically enhanced plants); production of pathogen-free plants (studies in abilities to stop infection of plants by viruses, bacteria and fungi); germplasm storage (studies in the conservation of genetic resources); and product formation (studies in a large number of plant-based chemicals of pharmaceutical and industrial interest). Of these applications, it is in the production of genetically enhanced plants that the application of tissue culture is used most today. Techniques of transforming plants utilize re-generable organs such as leaves, stems and roots through tissue culture to engineer important traits, for example the control of insects, weeds and plant diseases that drastically reduce yield as well as to introduce nutritional qualities and to increase yield (Stewart, 2008; Dunwell \& Wetten, 2012).

We describe an initiative where a multi-week inquiry-based laboratory module in plant tissue culture was implemented in a botany course primarily enrolling sophomore and junior level students. Plant tissue culture is based on the theory of totipotency, that is, the genetically based ability of a cell or a non-embryonic organ to form all the cell types in the adult organism. The first step in many tissue culture experiments is the induction of callus formation from an explant. This explant may be in vitro germinating plantlets or surface sterilized roots, stems, leaves, or reproductive organs. Callus is a wound tissue produced in response to injury. Within an explant not all cells contribute to the formation of callus and, more importantly, all callus cell types are not competent to regenerate organized structures. The selection or development of a culture medium is vital to the successful growth of callus or a complete plant in tissue culture. No single medium will support the growth of all cells, and changes in the medium are often required for different types of growth response from a single explant. A literature search is useful for selecting the appropriate medium. If literature on the plant is not available, the development of suitable medium is based on trial and error. The approach to developing the medium will depend on the purpose of the cell culture (e.g. whether it is for callus induction, somatic embryogenesis, anther culture or shoot proliferation).

The main goal was to expose the students to an inquiry-based lab module which would allow them to learn the effects of hormones on plant development and methods to develop callus tissue while gaining practical experience in sterile techniques, media preparations, and in vitro vegetative propagation as well as to develop skills in hypothesis formation and in basic data analysis. At the end of the semester the students were required to submit a journal-style lab report discussing their findings including at least 6 primary literature sources. This aspect of the exercise, as well as discussions during the semester, exposed the undergraduate students to proper information literacy. Initially, the lab module was pilot tested in one laboratory section (approximately 20 students) and compared to another section (approximately 20 students) with the traditional sequence of laboratory exercises. Both of these sections were taught in the same semester by the same graduate teaching assistant (GTA) to minimize any GTA-related bias. The module was then modified and optimized before implementing to the entire course population (full implementation) of approximately 140 students per year.

\section{Methodology}

African violet (Gloxinia sp., Fam. Gesneriaceae) was used as the plant material for this module primarily due to the availability of previous studies in its tissue culture practices as well the possibility to conclude the module within a 15-week semester (Bilkey et al., 1978). The exercises pertaining to this module were conducted in teams of 4 students in the lab sessions during weeks 2, 3, 10 and 14 (Figure 1). Each lab section consisted of approximately 24 students. 

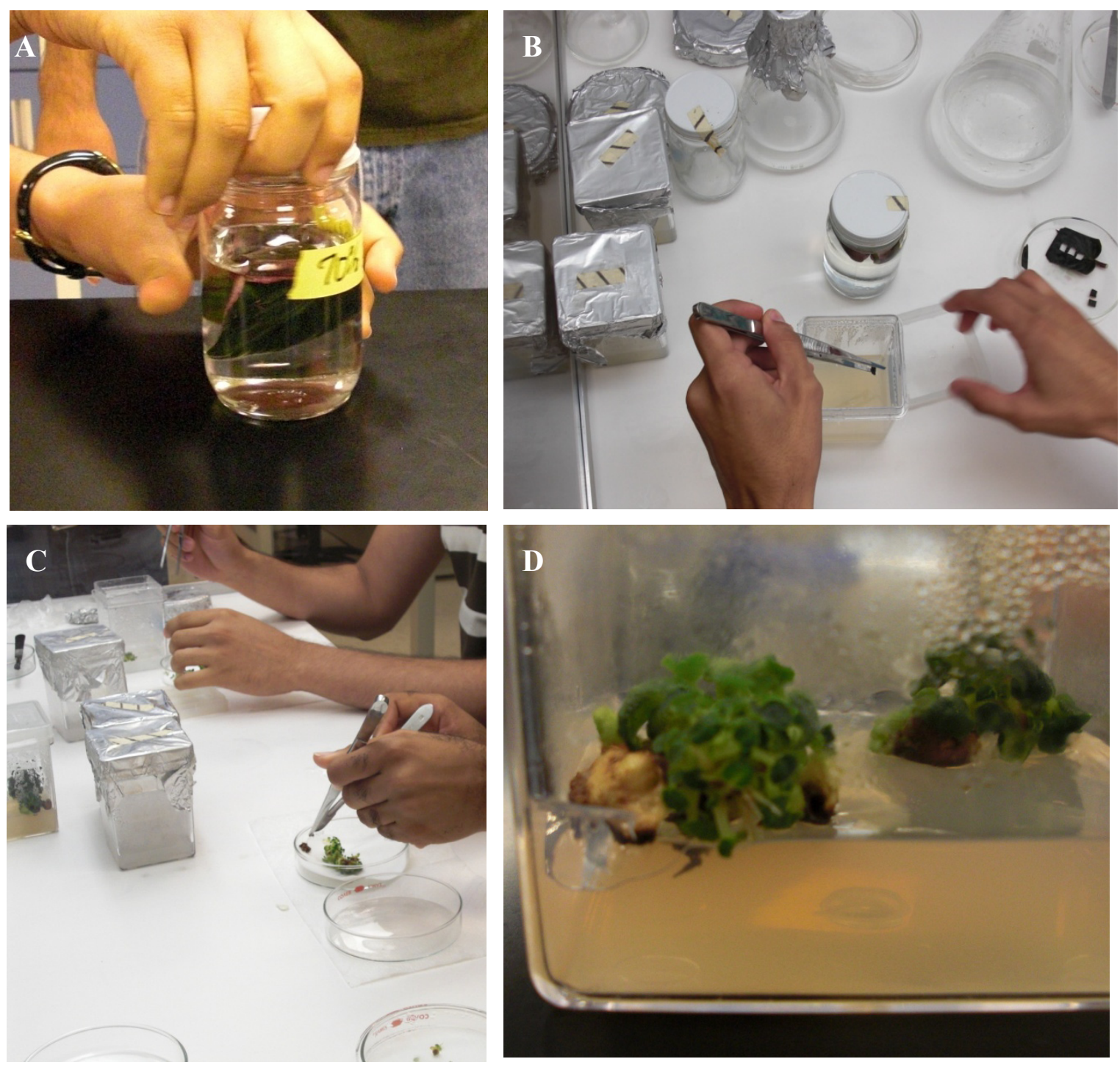

Figure 1. Implementation of the plant tissue culture inquiry-based laboratory module

Discription: (A) Students surface sterilize African violet leaves through washes in $70 \%$ ethanol and $10 \%$ sodium hypochlorite; (B) Each student cuts 4 explants $\left(25-30 \mathrm{~mm}^{2}\right.$; containing part of the mid-vein) from the sterilized leaves and place them on magenta boxes containing multiplication media; (C) Seven weeks later the resulting callus tissue with budding plantlets are transferred to petri dishes containing modified or unmodified pre-transplanting media; (D) After four more weeks, the growth and development of the plantlets are assessed.

\subsection{Sterile Techniques and Media Preparation (Week 2 of the Semester)}

Each group prepared 2 types of media: multiplication media and pre-transplanting media. Multiplication media contains $2 \mathrm{mg} / \mathrm{L}$ kinetin and $2 \mathrm{mg} / \mathrm{L}$ Indole acetic acid (IAA). Each group prepared the pre transplanting media with one component modified, such as increased kinetin, increased IAA, reduced sucrose or increased sucrose, etc. One group prepared unaltered pre-transplanting media (control) which already contained $1 \mathrm{mg} / \mathrm{L}$ of IAA. The stock powder for multiplication media and pre-transplanting media contains the appropriate levels of macro- and micro-nutrient necessary for the development of African violet (Carolina Biological or Phytotech Inc). In preparing the media for tissue culture $30 \mathrm{~g} / \mathrm{L}$ of sucrose and $8 \mathrm{~g} / \mathrm{L}$ agar as a solidifying agent were added. During this lab period the students also discussed the development of the hypothesis that were being tested in the module, learned sterile techniques ranging from cleaning of a laminar flow hood, appropriate behavior within the work area, sterilization of tools and media through autoclaving and sterilization of tools by flame. 


\subsection{In Vitro Multiplication of African Violet (Week 3 of the Semester)}

Each group selected, excised and surfaced sterilized 4 young African violet leaves. After excision, the leaves were washed with soap, rinsed 3 times in distilled water, manually shaken in a jar of $70 \%$ ethanol for $30 \mathrm{sec}$, rinsed 3 times in distilled water and manually shaken again in a jar containing $10 \%$ sodium hypochloride (plus a drop of Tween 20) for 5 minutes (Figure 1A). The exercise was then continued within a laminar flow hood beginning with leaf being rinsed 3 times in sterile water. Each student then removed a sterile leaf and using sterile tools cut 4 explants $\left(25-30 \mathrm{~mm}^{2}\right)$ containing part of the mid-vein (Figure 1B). Each student placed 4 such explants, in a petri dish containing multiplication medium, with the mid-vein perpendicular to the surface. The dishes were sealed with parafilm, appropriately labeled and placed in a plant growth incubator (Percival) under fluorescent lights (16/8 hours day/night) and $27^{\mathrm{OC}}$ for 7 weeks.

\subsection{In Vitro Transplanting of Plantlets (Week 10 of the Semester)}

Each student, using sterile techniques, carefully removed the callus with budding plantlets from the multiplication media and place in sterile petri dishes containing pre-transplanting media (Figure 1C). Using sterile tools, the callus was separated into individual clumps or plantlets and transferred into each group's pre-transplanting medium with 4 explants per petri dish. The petri dishes were then sealed, labeled and maintained for 4 weeks, as described previously.

\subsection{Analysis of Results (Week 14 of the Semester)}

All groups of a lab section evaluated the development of their plantlets grown on modified pre-transplanting mediums (Figure 1D). The development of shoot and root were compared to plantlets growing in the control plates containing $1 \mathrm{mg} / \mathrm{L}$ of IAA. By having many modified pre-transplanting mediums per lab section, the students were able to visualize the effects of different components on plant development. The results, which depended on the work performed by all lab groups led to overall discussions between groups, promoting team-work. The students had to complete a worksheet in-class as well as submit a lab report, with basic statistical analysis of the data, following the format of a research article, including title, author information, abstract, introduction, methods, results, discussion and references.

\subsection{Training}

The lab coordinator and GTAs were trained in the new techniques prior to the pilot implementation and thereafter the new GTAs were trained at the beginning of each semester during full implementations. It was vital to conduct a thorough training in order to successfully implement the module as the GTAs of our department lack prior exposure to tissue culture techniques and practices.

\subsection{Assessment Tools}

Tools were developed to assess gain of content knowledge and gain of self-confidence. The initial tool used to assess content knowledge gain consisted of 7 questions (Figure 2), both specific and general in nature, which was modified by the elimination of 2 questions after the pilot implementation due to the initial high score achieved by the students in the pre-module assessment tool (Figure 2). All questions, in the pre- and post-module assessment tool, included an 'I do not know' option, which not only minimized guessing by the students but also can be used to gauge any increase of confidence to answer the content questions. Furthermore, included in the post-module assessment tool were open-ended questions to allow the students to provide additional comments regarding their experiences with the laboratory module. Such suggestions were evaluated and changes made accordingly before the next implementation. To assess the gain of confidence by the students as a result of this module, a post-module tool was developed that assessed self-perception of knowledge of fundamental concepts in research-oriented sciences. These general concepts included self-confidence to 'make use of primary literature', 'construct a testable hypothesis', 'design an experiment to test a hypothesis', 'identify appropriate controls in an experiment' etc. Comparatively, this tool also included self-perception on specific gain of confidence such as confidence to 'propagate plants under tissue culture conditions'. All perception inquiries were developed using a 5-point Likert scale (Likert, 1932). 


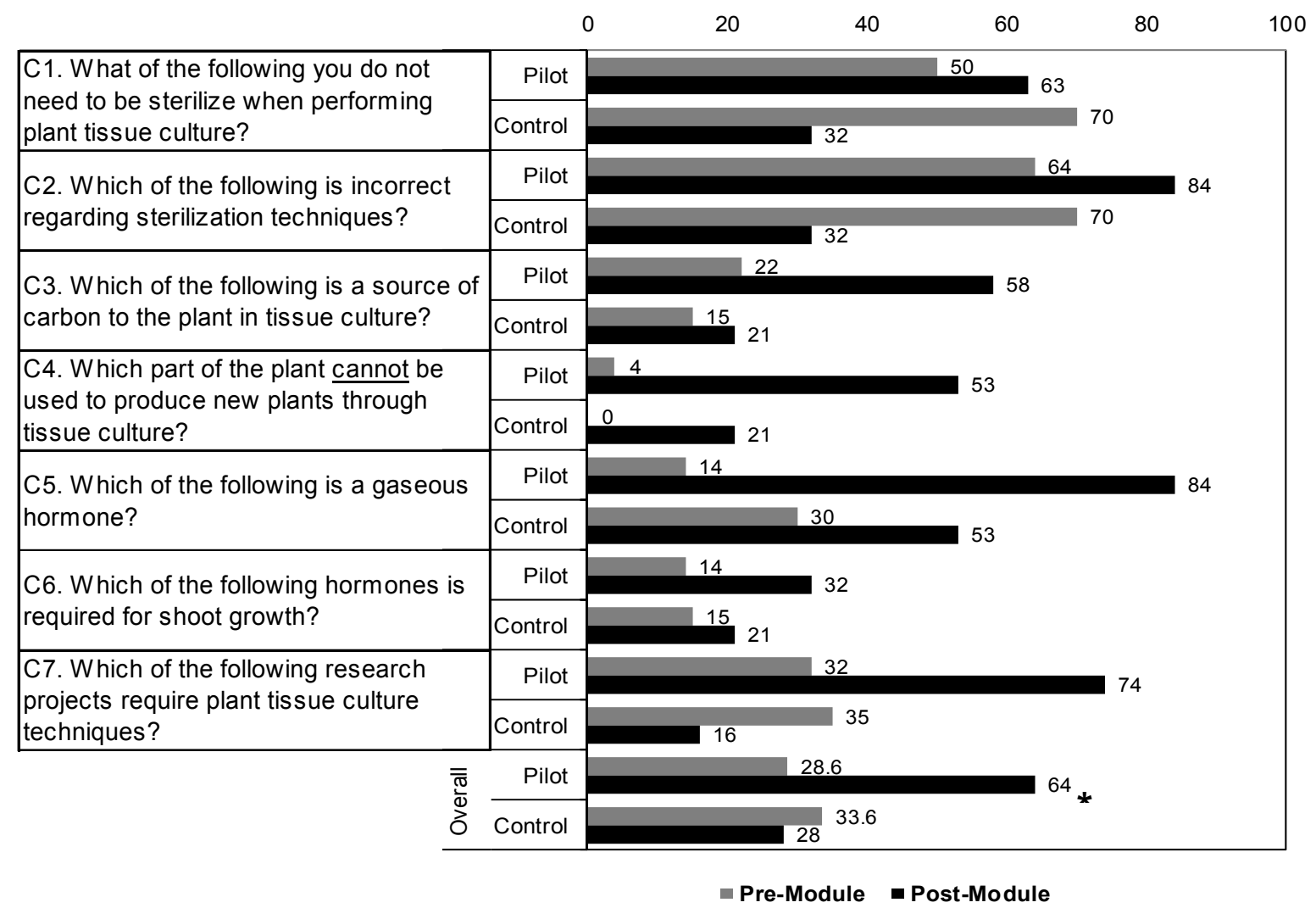

Figure 2. Content knowledge gained by students during the initial pilot implementation of the inquiry based laboratory module

Discription: The assessment tool, consisting of 7 questions, was used pre- and post-module implementation in the pilot (with new lab exercise) and control (traditional exercise) laboratory sections ( 20 students each). Percentage correct per question in the pre-module (gray columns) and post-module (black columns) assessments are shown. The last horizontal bars show the overall percentages. The overall test score in the post test was higher in the pilot section than in the control section $\left({ }^{*} \mathrm{p}<0.01\right)$ as determined using a paired $t$ test.

\section{Results and Discussion}

\subsection{Sterile Techniques}

Each student learnt proper sterile techniques ranging from sterilizing media and tools, appropriate behavior when working within a laminar flow hood, handling of ethanol flame to sterilize tools being used, handling of tissue culture tubes and vessels with sterile media both within and outside of the laminar flow hood etc. The students also prepared and then poured sterile media within the confinement of a laminar flow hood. In general, contamination with microorganisms was not observed due to the lack of proper practices as described above but some contamination was observed once sterilized plant material was placed within the sterile containers containing media. The African violet explants used were growing in soil and were not from tissue culture. This was purposely done to give the students experience transferring explants from in vivo to in vitro conditions. However, this led to approximately $40 \%$ of the vessels being contaminated with bacteria and/or fungus. The GTAs used the contaminated vessels as an education tool to discuss not only short-comings of the surface sterilization practices utilized in this exercise but also steps that could be taken to prevent such contamination in the future (such as more time in ethanol and sodium hypochloride, higher concentrations of these, use of smaller and younger ex-plants).

\subsection{Plant Tissue Culture Practices}

Each individual student conducted plant tissue culture under sterile conditions thus exposing each student to a valuable experience in plant sciences. Approximately $65 \%$ of the explants resulted in callus formation and of those approximately $75 \%$ led to plantlet development in the multiplication media. We considered this a success 
when taking into account that all procedures were conducted by untrained undergraduate students. During the 7 week period, from week 3 to 10, the students observed the development of callus and then plantlets during lab sessions 7 and 9 without opening the vessels. After transferring the young plantlets from multiplication media to pre-transplanting media (modified and unmodified) in week 10 lab session the students formed different hypothesis based on the different modifications done to the pre-transplanting media. Plantlets in modified pre-transplanting media grew at different development rates compared to the unmodified pre-transplanting media, in both shoot and root, and were rarely contaminated (no contamination in approximately $95 \%$ of the plantlets). This can be attributed to gain of experience, from week 3 , in performing better sterile tissue culture practices. Overall, the best observable results, different from unmodified pre-transplanting media, were obtained in media containing reduced sucrose as the modification, followed by increased IAA as the modification. Although the students worked in groups each student gained valuable experience in plant tissue culture techniques, otherwise not available through any other course on campus.

\subsection{Assessment of Student Learning}

The overall objective of this laboratory module implementation was to introduce students to an inquiry-based research exercise in plant sciences that differed from the traditional cook-book style lab exercise. In this context we aimed to educate students not only in proper sterile techniques and plant tissue culture techniques but also expose the students to varying effects of different components of a tissue culture media. Through this hands-on practical experience, we also aimed to enhance students' confidence in performing, learning and understanding inquiry-based experimental science. To assess the impact of this module, knowledge and confidence building assessment tools were used at the beginning (week 1) and end (week 15) of the semester. The gain-of content knowledge assessment tool used showed higher knowledge gained by students in the pilot section (with the new lab module) compared to students in the control group (in traditional lab without the new lab module) also taught by the same GTA (Figure 2). The students in both sections scored similarly in the pre-module assessment (pilot section test score average of $\sim 28 \%$ and control section $\sim 34 \%$ ) but in the post-module assessment the students in the pilot section increased to $64 \%$ while the students in the control section marginally decreased to $28 \%$. In order to further optimize the gain-of content knowledge assessment tool two of the questions, $\mathrm{C} 1$ and $\mathrm{C} 2$, were subsequently eliminated due to the high scores in the pre-module assessment of $50 \%$ and $70 \%$, respectively. During the full-implementation of the module approximately 140 students per year were exposed to the new module. In each semester the overall average student scores in the pre-module assessment was approximately $22-26 \%$, but in the post-modules assessment the students' average scores increased by 2.37 fold (55.3\%), 2.33 fold (61.6\%) and 2.84 fold (63.1\%) in Sp10, Fall10 and Sp11 semesters, respectively (Figure 3). The highest increase was observed consistently with question $\mathrm{C} 4$ which showed 10.75 fold, 27.93 and 8.59 fold increase between the pre- and post-module assessments during the three semesters (Figure 3). In general terms, as expected, the more specific assessment questions (C3 - C5) showed more dramatic increase between the pre- and post-module assessments compared to the more general questions (C6 - C7). This may be due primarily to the exposure of the students to the more general concepts regarding plant hormones in the introductory biology courses, thus resulting in higher pre-module scores. Overall, there was a significant increase, between the preand the post-module assessments, in the students' ability to correctly answer content questions. 


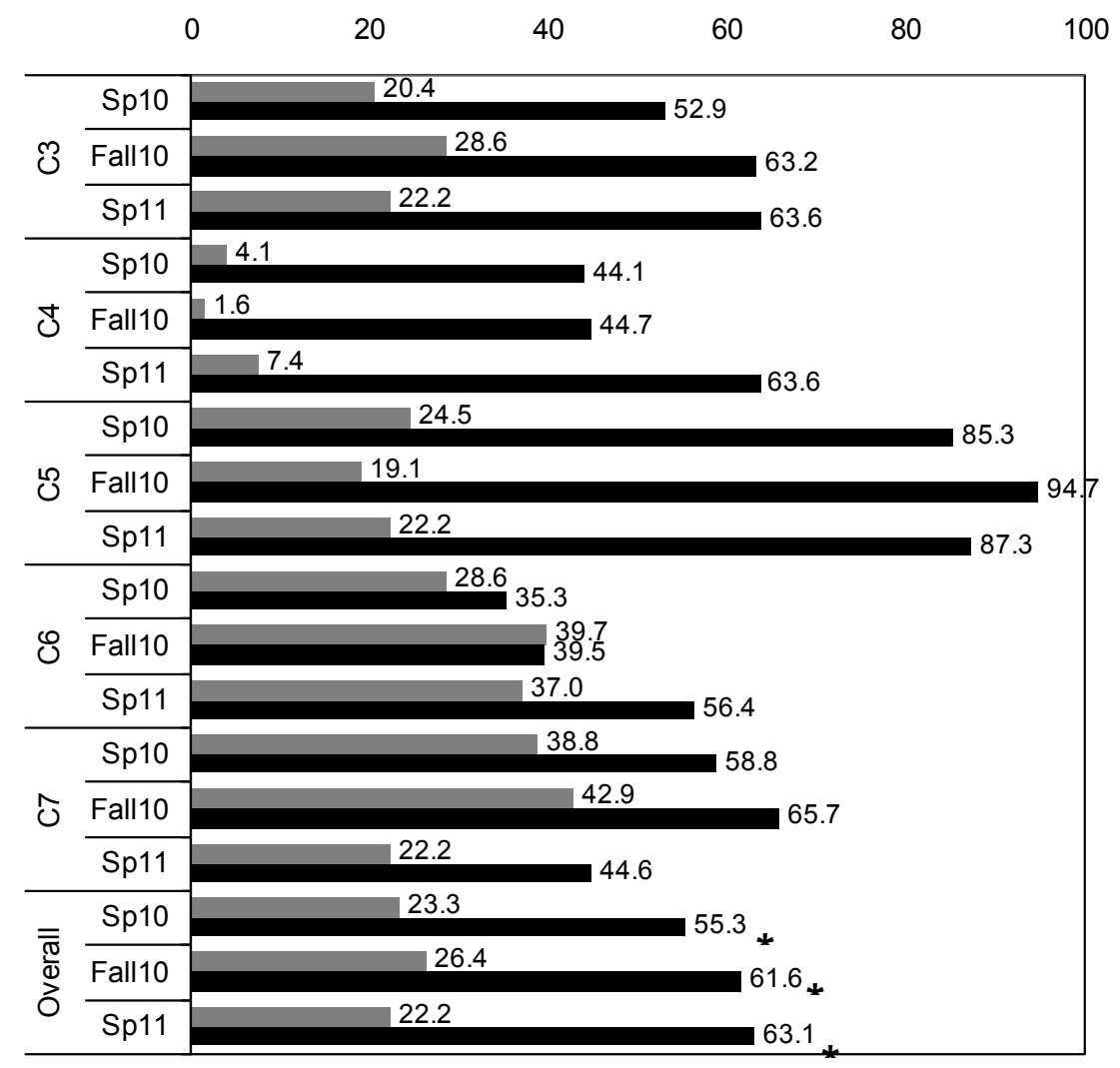

\section{- Pre-Module a Post-Module}

Figure 3. Content knowledge gained by the students during three semesters of full-implementations of the inquiry-based laboratory module

Discription: Questions C1 and C2 (Figure 2) were eliminated from the assessment tool after the pilot study due to the high score achieved by the students in the pre-module assessment. Percentage correct per questions in the pre-module (gray columns) and post-module (black columns) assessments during Sp10, Fall11 and Sp11 semesters are shown. The last horizontal bars show the test overall average for each semester. The overall scores in the post tests were higher $\left({ }^{*} \mathrm{p}<0.01\right)$ than in the pretest as determined using a paired $t$ test.

To gauge the confidence of students to attempt answering content questions, each question contained an answer choice of 'I do not know' in both the pre- and post-module assessments. In each question, between the pre- and post- module assessments, there was a marked reduction in the percentage of students who marked 'I do not' know', thus revealing an increase of confidence to attempt answering each question (Figure 4A). During the pilot implementation $32.6 \%$ and $29.3 \%$ of the students answered 'I do not know' overall in the pre-module assessment of the pilot section and control section, respectively (Figure 4B). Comparatively, in the post-module assessment in the pilot section the overall \% of students marking 'I do not know' drastically reduced to $3.7 \%$ while in the control section there was minimal increase to $37.4 \%$. Similar trend was also observed in the subsequent three semesters of full-implementation where there was a significant increase in the percentage of students attempting to answer the content questions in the post-module assessment compared to the pre-module assessment (Figure 4B). This increase in confidence to attempt answering the questions can be directly attributed the hands-on inquiry-based nature of the laboratory module where the students are compelled to think beyond the weekly laboratory practice, which is not the case with most cook-book style laboratory exercises. 
(A)

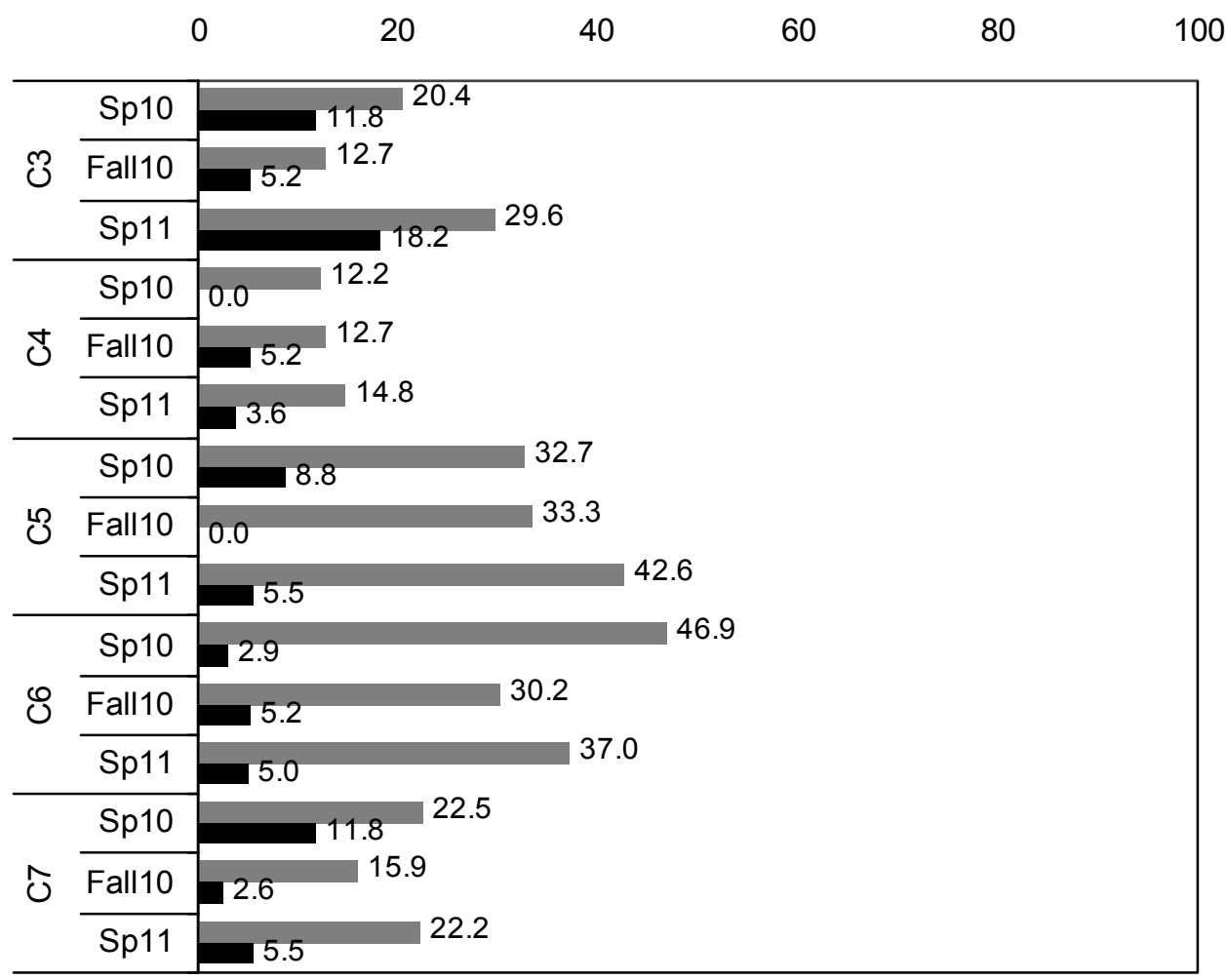

- Pre-Module — Post-Module

(B)

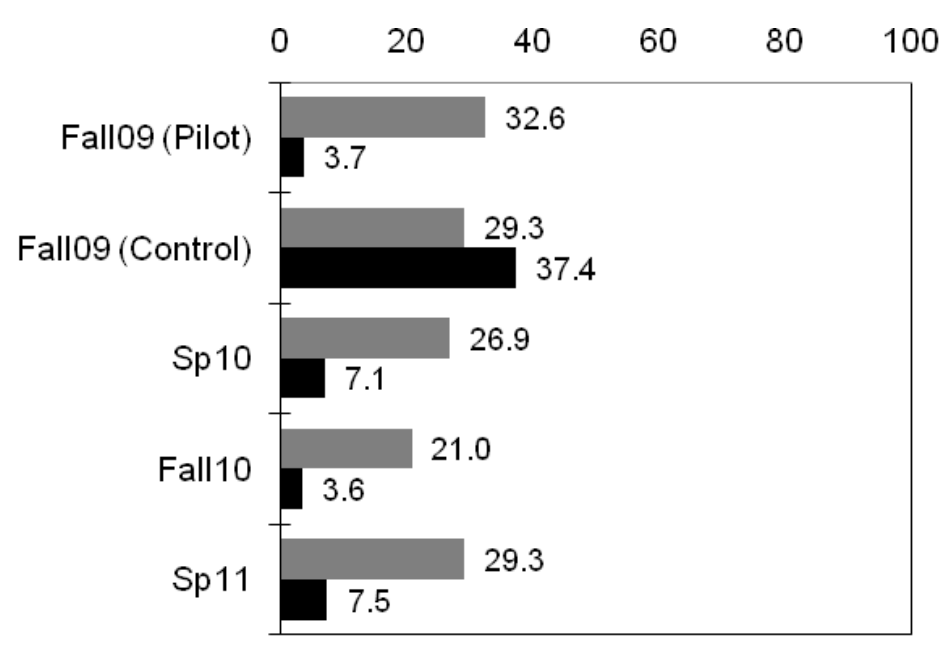

- Pre-Module a Post-Module

Figure 4. Gain of confidence in students determined by them answering the content knowledge questions

Discription: The percentages reflect the average number of students who answered 'I do not know' per questions in the pre- and post-module assessments in the three semesters of the full implementation (A) and the overall in the pilot testing semester and the three semesters of full implementation (B). The overall scores in the post tests were lower $\left({ }^{*} \mathrm{p}<0.01\right)$ as determined using a paired $t$ test.

To further assess if the laboratory module had an impact on students confidence, a post-module assessment tool using a 5-point Likert scale was used (Figure 5; Likert, 1932). Contrary to the previous method in assessing confidence (via 'I do not know' answer choice), this assessment tool relied upon self-reporting of confidence regarding gaining research skills and techniques. During Sp10, Fall10 and Sp11 semester, of the 12 categories (P1 - P12) used, $>50 \%$ of the students self-reported as 'very confident' or 'confident' in 8,11 and 12 categories, 
respectively. Furthermore, there was a consistent increase of the $\%$ of students self-reporting as 'very confident' or 'confident' from Sp10 to Sp11 semesters in each of the categories. This, we believe is attributable to the increased confidence and efficiency of the laboratory coordinator and GTAs who conduct the laboratory exercises. Of significance is the confidence reported in 'make use of primary scientific research literature' (P2), 'observe and collect data' (P6) and 'perform well in scientific research projects' (P11) where an average of 63\%, $78 \%$ and $72 \%$ of the students during the three semesters reported 'very confident' and 'confident' as a result of participating in this lab module (Figure 5). We believe such increases in self-confidence early in the career of biology majors are very important. AT UPRM there is limited access to research opportunities for the majority of the biology majors in our department. Through the inquiry based laboratory modules described here we were able to impact of a greater number of students. Furthermore, because of preparing the inquiry-based lab module in plant tissue culture the students were also exposed to a novel field of agricultural biotechnology, which utilizes sterile techniques in plant tissue culture as a method to research and develop transgenic food sources.

Furthermore, implementing this module in the botany lab allowed for academic empowerment of our GTAs and lab coordinator, who are traditionally over-looked in initiatives aimed at impacting undergraduate education. All support personnel involved in this module implementation were botanists with little to no experience in plant tissue culture, but now have mastered the research tools and techniques of this field. Assessments conducted on the GTAs and lab coordinator revealed their enthusiasm and support towards this initiative as well their gain of knowledge and confidence in plant tissue culture (data not shown).

We believe that our module is a strategy that could be easily transferred and established in other institutions of higher education. We have demonstrated that moving away from traditional cook-book style laboratory exercises, where anticipated results can be easily obtained, and implementing more inquiry-based exercises increases students' awareness about modern day experimentations, enhance self-confidence in conducting research as well as learning novel techniques, and enhance understanding and retention of content knowledge central to that particular discipline as promoted in the American Association for the Advancement of Science's Vision and Change in Undergraduate Biology Education (AAAS, 2011). This is of great importance when attempting to increase the number of qualified and well-prepared work force in Science, Technology, Engineering and Mathematics fields in the future, which is crucial for the progression of science and its products to benefit mankind (Mervis, 2009; National Research Council, 2009; Woodin, Smith, Allen, 2009). 


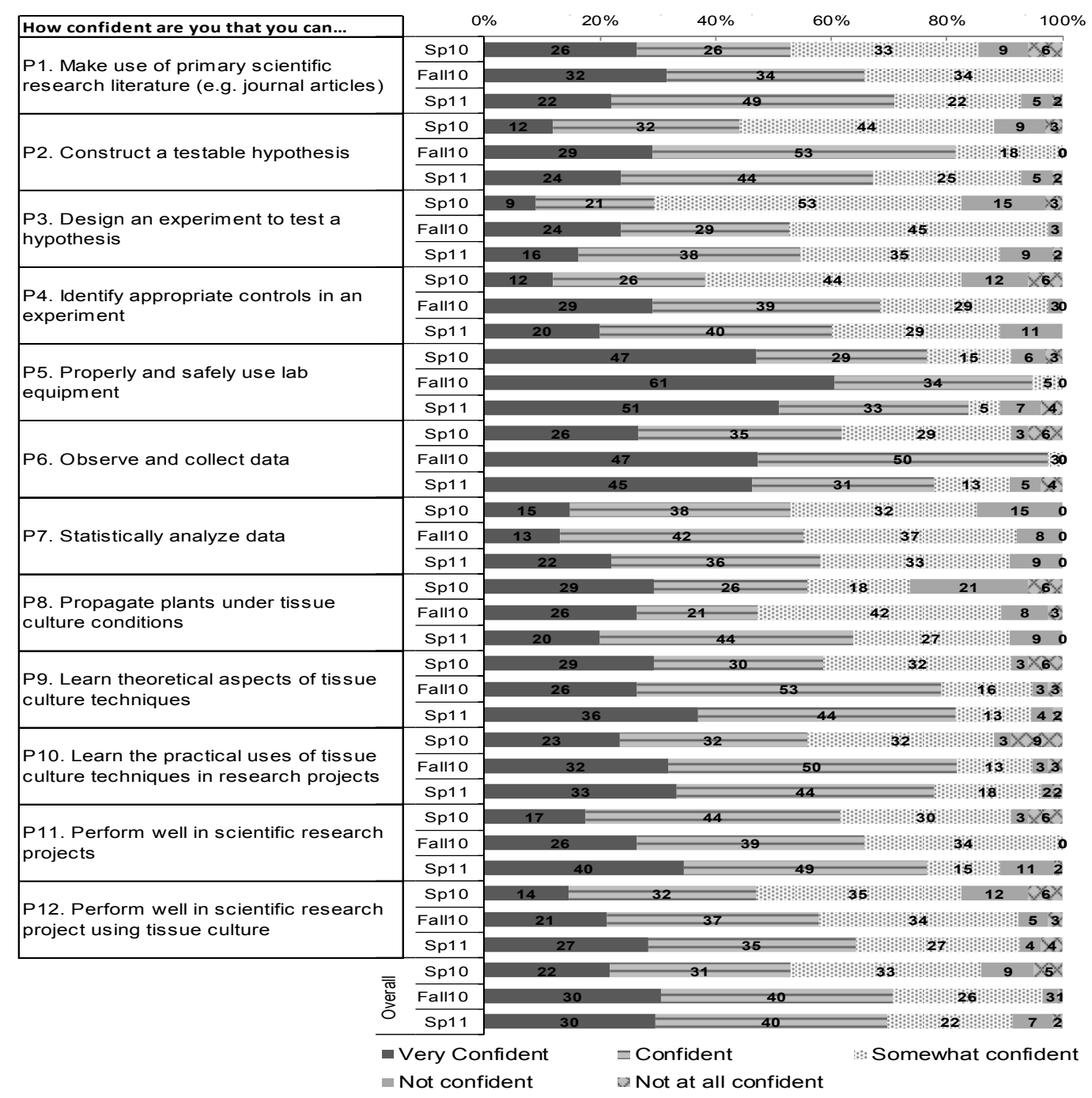

Figure 5. Self-confidence regarding research skills and techniques gained by students during the three semesters of full-implementations of the inquiry-based laboratory module.

Discription: The assessment tool consisted of 12 self-evaluatory questions measured using a 5-point Likert scale ( 5 = very confident, $4=$ confident, $3=$ somewhat confident, $2=$ not confident and $1=$ not at all confident $)$.

\section{Acknowledgements}

We would like to express our gratitude to Dr. Jarrod Thaxton, who is the laboratory coordinator for Biol3417 course, for his contributions in the implementation of this module from the inception as well as for critically reviewing this manuscript. We also thank the GTAs of Biol3417 course during Fall09, Sp10, Fall10 and Sp11 semesters and Maria Mendez for their efforts and participation in conducting assessment. This project was funded by the Undergraduate Science Education Program of the Howard Hughes Medical Institute 2008-2012 (\#52006318).

\section{References}

American Association for the Advancement of Science (AAAS). (2011). Vision and Change in undergraduate Biology Education: A Call to Action, Washington, DC. Retrieved April 30, 2012, from http://visionandchange.org/finalreport

Bilkey, P. C., McCown, B. M., \& Hildebrandt, A. C. (1978). Micropropagation of African violet from petiole cross-sections. HortScience, 13, 37-38.

Dunwell, J., \& Wetten, A. (2012). Transgenic plants: Methods and protocols. Humana Press Inc, New York, NY. 
Likert, R. (1932). A Technique for the Measurement of Attitudes. Archives of Psychology, 140, 1-55.

Lopatto, D. (2010). Science in Solution: The Impact of Undergraduate Research on Student Learning. Tucson, AZ: Research Corporation for Science Advancement. Retrieved April 30, 2012, from $\mathrm{http}: / /$ web.grinnell.edu/sureiii/Science_in_Solution_Lopatto.pdf

Mervis, J. (2009). Universities begin to rethink university biology courses. Science, 375(527). http://dx.doi.org/10.1126/science.325_527a

National Research Council. (2003). Transforming Undergraduate Education for Future Research Biologist. Washington, DC: National Academies Press. Retrieved April 30, 2012, from www.nap.edu/catalog.php?record_id=10497

National Research Council. (2009) A New Biology for the 21st Century. Washington, DC: The National Academies Press. Retrieved 11 June, 2012, from http://books.nap.edu/catalog.php?record_id=12764

Russell, S., Hancock, M. P., \& McCullough, J. (2007). Benefits of Undergraduate Research Experiences. Science, 316, 548-549. http://dx.doi.org/10.1126/science.1140384

Shaffer, C. D., Alvarez, C., Bailey, C., Barnard, D., Bhalla, S., Chandrasekaran, C., ... Elgin, S. C. (2010). The genomics education partnership: successful integration of research into laboratory classes at a diverse group of undergraduate institutions. CBE - Life Science Education Journal, 9, 55-69. http://dx.doi.org/10.1187/09-11-0087

Siritunga, D., Montero-Rojas, M., Carrero, K., Toro, G., Vélez, A., \& Carrero-Martínez, A. (2011). Culturally relevant research to the masses: Large-scale laboratory module implementations in upper-division genetics and cell biology teaching laboratories, CBE - Life Science Education Journal, 10, 287-297. http://dx.doi.org/10.1187/cbe.11-04-0035

Stewart, C. N. (2008). Plant Biotechnology and genetics: Principles, techniques and applications. John Wiley and Sons, Inc, Hoboken, NJ. http://dx.doi.org/10.1002/9780470282014

Wei, C., \& Woodin, T. (2011). Undergraduate Research Experiences in Biology: Alternatives to the Apprenticeship Model, CBE - Life Sciences Education, 10, 123-131. http://dx.doi.org/10.1187/cbe.11-03-0028

Woodin, T., Smith, D., \& Allen, D. (2009). Transforming Undergraduate Biology Education for All Students: An Action Plan for the Twenty-First Century, CBE - Life Sciences Education, 8, 271-273. http://dx.doi.org/10.1187/cbe.09-09-0063 